Arq. Bras. Med. Vet. Zootec., v.71, n.1, p.243-251, 2019

\title{
Efeito de diferentes tempos de exposição ao calor e de linhagens sobre o rendimento de carcaça e a composição química de peito de frangos de corte
}

\author{
[Effect of different timing of exposure to heat and strains on the carcass yield and breast \\ chemical composition of broiler] \\ A.M. Santos ${ }^{1}$, M.R.B.M Nascimento ${ }^{2}$, J.P.R. Bueno ${ }^{1}$, L.R.M. Gotardo ${ }^{1}$, F.H. Litz $^{1}$, \\ O.C.L. Olivieri ${ }^{3}$, R.L.O.R. Alves ${ }^{3}$, E.C. Guimarães ${ }^{2}$ \\ ${ }^{1}$ Aluno de pós-graduação - Universidade Federal de Uberlândia - Uberlândia, MG \\ ${ }^{2}$ Universidade Federal de Uberlândia - Uberlândia, MG \\ ${ }^{3}$ Aluno de graduação - FAMEV - Universidade Federal de Uberlândia - Uberlândia, MG
}

\begin{abstract}
RESUMO
Investigaram-se os efeitos de diferentes tempos de exposição ao calor sobre o rendimento de carcaça, cortes e vísceras comestíveis e a composição química da carne de peito de frangos de corte de duas linhagens. Foram alojados 560 pintos de corte da linhagem Cobb 500 Slow e 560 da Hubbard Flex® em 32 boxes. A partir do $14^{\circ}$ dia, eles foram divididos nos ambientes térmicos: controle, uma hora, duas horas ou três horas diárias de estresse por calor. O rendimento de carcaça, peito sem osso, coxa e sobrecoxa com osso, asas, pés, fígado, moela e coração foi avaliado em seis aves de cada linhagem em cada ambiente térmico. Amostras foram obtidas para analisar matéria seca, extrato etéreo, proteína bruta e matéria mineral. $\mathrm{O}$ estresse cíclico por calor por até três horas diárias não influenciou o rendimento de carcaça, de peito sem osso, de coxa e sobrecoxa, de asa, de coração, de moela, de fígado e a composição química do peito. A linhagem Cobb 500 Slow ${ }^{\circledR}$ apresentou maior rendimento de peito. A Hubbard Flex ${ }^{\circledR}$ apresentou peito com maior percentual de matéria mineral e proteína. A linhagem Cobb é mais indicada à produção de peito, e a linhagem Hubbard à produção de frango inteiro.
\end{abstract}

Palavras-chave: ave, estresse por calor, vísceras comestíveis

\begin{abstract}
The effects of different exposure periods under heat on the carcass yield, cuts and edible organs and breast chemical composition of broilers from two strains were investigated. Five hundred and sixty Cobb 500 Slow ${ }^{\circledR}$ and 560 Hubbard Flex ${ }^{\circledR}$ broiler chicks were housed in 32 pens and from the $14^{\text {th }}$ day on, they were divided in thermal environments: control, 1 hour, 2 hours or 3 hours a day under heat stress. Carcass yield, boneless breast, thigh and drumstick with bone, wings, feet, liver, gizzard and heart were evaluated in six birds of each strain in each thermal environment. Samples were obtained to assess dry matter, ether extract, crude protein and mineral matter. The cyclic heat stress for up to three hours a day did not influence 33 the carcass yield, boneless breast, thigh and drumstick, wing, heart, gizzard, liver, and the breast chemical composition. Cobb 500 Slow ${ }^{\circledR}$ strain had higher breast yield. Hubbard Flex ${ }^{\circledR}$ had breast with higher percentage of mineral matter and protein. Cobb strain is best designed to breast production, and Hubbard is best for whole chicken production.
\end{abstract}

Keywords: poultry, $m$ thermal comfort, heat stress, edible organs

\section{INTRODUÇÃO}

A temperatura ambiente elevada ainda é um desafio na produção de frangos de corte. No Brasil, especialmente na região Central, a variação da temperatura nas 24 horas do dia é

Recebido em 12 de janeiro de 2017

Aceito em 14 de fevereiro de 2018

E-mail: alinems8787@gmail.com cíclica: aumenta das oito horas até aproximadamente às 16 horas e, a partir daí, decresce, alcançando menores valores por volta das cinco horas. Assim, o estresse cíclico por calor, ou seja, algumas horas diárias de temperatura elevada, e as demais horas em conforto térmico podem prejudicar o desempenho e o bem-estar dos animais. 
A literatura que trata do tempo de exposição ao estresse cíclico por calor apresenta metodologias variáveis, ora é de uma hora, ora de três horas, ora de seis horas (Zhang et al., 2014), ora é de 72 horas, em diferentes idades de criação (Mello et al., 2015). Portanto, ainda há necessidade de mais pesquisas que avaliem os efeitos de diversos tempos de exposição ao calor, bem como comparem as respostas de diferentes linhagens comerciais.

A maior eficiência nutricional e o rápido desenvolvimento foram priorizados pela seleção de linhagens de frango, entretanto as aves continuaram apresentando maior susceptibilidade ao estresse por calor (Antonio, 2010). Estudos têm sido realizados para avaliar as linhagens e suas melhores características. Silva (2013) observou que diferentes linhagens proporcionam diferentes rendimentos de cortes comerciais, tendo a Cobb maior rendimento de peito e a Hubbard maior rendimento de coxa e sobrecoxa.

Pela necessidade de mais estudos que avaliem o efeito de diferentes tempos de exposição ao calor, objetivou-se, no presente estudo, investigar se o rendimento de carcaça, cortes e vísceras comestíveis bem como a composição química da carne de peito de frangos das linhagens Cobb 500 Slow ${ }^{\circledR}$ e Hubbard Flex ${ }^{\circledR}$ são afetados quando submetidos a uma, duas ou três horas diárias de aquecimento do $14^{\circ}$ ao $41^{\circ}$ dia de idade.

\section{MATERIAL E MÉTODOS}

Todos os procedimentos nesta pesquisa foram realizados conforme Protocolo Registro Ceua/UFU no 065/2014, aprovado pelo Comitê de Ética na Utilização de Animais da Universidade Federal de Uberlândia (Anexo A). O experimento foi realizado na Granja de Experimentação de Aves, na Fazenda do Glória, da Universidade Federal de Uberlândia, MG, Brasil (18 $58^{\circ} \mathrm{S}, \quad 48^{\circ} 12^{\prime} \mathrm{O}$ e $889,02 \mathrm{~m}$ de altitude), de abril a maio de 2015 .
O galpão é construído em alvenaria e estrutura metálica, cobertura de telhas de fibrocimento, piso concretado, paredes laterais teladas e protegidas com cortinas laterais internas e externas, forrado com tecido plástico, equipado com ventiladores e nebulizadores.

Foram alojados 1120 pintos de corte, machos, com um dia de idade, sendo 560 da linhagem Hubbard Flex® e 560 da linhagem Cobb 500 Slow ${ }^{\circledR}$, distribuídos em 32 boxes (1,50 x 1,90m), forrados com maravalha, sendo cada boxe equipado com um bebedouro pendular e um comedouro tubular para $25 \mathrm{~kg}$ de ração. Do primeiro ao $13^{\circ}$ dia de idade, todas as aves foram mantidas em condições naturais de temperatura e umidade. Durante o período de estresse, a partir do $14^{\circ}$ dia, o galpão foi separado transversalmente com cortinas plásticas de dupla face, dobradas de modo a expor a face branca em quatro câmaras paralelas de 5,60m de largura $\mathrm{x}$ 10,20 m de comprimento x 2,80 de altura.

Dessa forma, criaram-se quatro ambientes térmicos, compostos por oito boxes, sendo quatro boxes de cada linhagem. No ambiente controle, as aves permaneceram em condições naturais de temperatura e umidade até o abate. Nas outras câmaras, as aves foram submetidas a temperaturas elevadas por uma hora (11h-12h), duas horas (11h-13h) e três horas (11h-14h) até o $41^{\circ}$ dia. Campânulas de infravermelho foram utilizadas para o aquecimento com temperaturas $10^{\circ}$ acima do conforto térmico: $36^{\circ} \mathrm{C}$, de $14-20$ dias; $35^{\circ} \mathrm{C}$, de $21-27$ dias; $34^{\circ} \mathrm{C}$, de $28-34$ dias; e $33^{\circ} \mathrm{C}$, de $35-42$ dias.

No período de estresse, a temperatura e a umidade do ar foram registradas de 10 em 10 minutos, utilizando-se um psicrômetro, com a finalidade de minimizar flutuações destas durante o período experimental (Tab.1). Nos períodos de aquecimento artificial, os ventiladores foram ligados para garantir aeração do ambiente, e água e ração ficaram disponíveis às aves. As condições ambientais do galpão também foram monitoradas diariamente a cada hora, por meio de data logger. 
Tabela 1. Médias e desvios-padrão da temperatura e da umidade relativa do ar, registradas durante período de estresse por calor, nos diferentes ambientes e idades de frangos de corte, Uberlândia, Minas Gerais, 2015

\begin{tabular}{|c|c|c|c|c|}
\hline & \multicolumn{3}{|c|}{ Controle } & \\
\hline & 14-20 dias & 21-27 dias & 28-34 dias & 35-41dias \\
\hline Temperatura $\left({ }^{\circ} \mathrm{C}\right)$ & $26,6 \pm 1,9$ & $25,9 \pm 1,7$ & $24,8 \pm 2,2$ & $27,0 \pm 1,6$ \\
\hline Umidade $(\%)$ & $63,9 \pm 5,5$ & $63,4 \pm 2,1$ & $67,9 \pm 6,3$ & $60,0 \pm 2,8$ \\
\hline \multicolumn{5}{|c|}{ Estresse* $(1 \mathrm{~h}, 2 \mathrm{~h}$ e $3 \mathrm{~h})$} \\
\hline & 14-20 dias & 21-27 dias & 28-34 dias & 35-41dias \\
\hline Temperatura $\left({ }^{\circ} \mathrm{C}\right)$ & $35,1 \pm 1,1$ & $34,2 \pm 0,9$ & $33,2 \pm 0,9$ & $32,3 \pm 0,8$ \\
\hline Umidade (\%) & $65,2 \pm 2,2$ & $55,3 \pm 1,5$ & $58,7 \pm 1,1$ & $60,3 \pm 2,0$ \\
\hline
\end{tabular}

*Registros realizados diariamente de 10 em 10 minutos, nos quatro ambientes, do início (11h) até o fim do aquecimento artificial (14h), para evitar flutuações das temperaturas.

Todas as aves receberam dietas à base de sorgo e farelo de soja, as quais foram elaboradas com níveis nutricionais baseados em Rostagno et al. (2011), e a matéria- prima foi bromatologicamente testada (Tab. 2). O programa alimentar compreendeu: ração préinicial (um a sete dias), inicial (oito a 21 dias), crescimento (22 a 33 dias) e final (34 a 42 dias), com alimentação e água livremente disponíveis. Durante o experimento, os valores de $\mathrm{CO}_{2}$ não ultrapassaram o recomendado $(<3000 \mathrm{ppm})$ para criação de frangos de corte. Os programas de luz de um a sete dias, de oito a 21 dias e de 22 a 42 dias de idade foram, respectivamente, de duas, quatro e duas horas sem luz.

Aos 41 dias, seis aves de cada ambiente térmico, com peso próximo da média de cada boxe $( \pm$ $5 \%$ ), foram separadas, identificadas e submetidas ao jejum de ração de oito horas e hídrico de quatro horas, para esvaziamento do trato digestório e, em seguida, foram abatidas de acordo com as normas e os procedimentos oficiais (Brasil, 1998) para se avaliar o rendimento de carcaça, cortes e vísceras comestíveis.

O rendimento de carcaça foi avaliado analisandose o peso da carcaça eviscerada com pés e cabeça em relação ao peso vivo em jejum. O peito com osso e sem osso, a coxa e a sobrecoxa com osso, as asas, os pés, o fígado, o coração e a moela foram pesados em balanças com precisão de $1 \mathrm{~g}$, e seus rendimentos calculados em relação ao peso da carcaça eviscerada.

Para avaliação da composição da carcaça, os músculos escolhidos para análise foram os mais representativos do total da carcaça, ou seja, os músculos do peito, que foram congelados e analisados pela composição centesimal no Laboratório de Nutrição Animal da Faculdade de Medicina Veterinária da Universidade Federal de Uberlândia, Uberlândia, MG. Os cortes foram descongelados e triturados até formarem uma pasta homogênea, pré-secos em estufa de circulação de ventilação forçada a $55^{\circ} \mathrm{C}$, por 72 horas, para análise de matéria seca, extrato etéreo, proteína bruta e matéria mineral, de acordo com a metodologia proposta pelo Compêndio Brasileiro de Alimentação Animal (Brasil, 2009).

Após apresentarem normalidade dos resíduos e homogeneidade das variâncias, os dados foram analisados no delineamento inteiramente ao acaso, em esquema de parcelas subdivididas, sendo parcelas o ambiente térmico e subparcelas a linhagem. Para comparar médias, foi aplicado o teste de Scott-Knott a 5\%. A análise estatística foi realizada por meio do software estatístico Sisvar (Ferreira, 2011).

\section{RESULTADOS E DISCUSSÃO}

No presente estudo, não houve interação ( $\mathrm{P}$ valor $>0,05$ ) entre o ambiente (zero hora, uma hora, duas horas e três horas de submissão a temperaturas elevadas) e a linhagem (Cobb 500 Slow® e Hubbard Flex $\left.{ }^{\circledR}\right)$ para todas as variáveis analisadas. O estresse cíclico por calor por até três horas diárias não influenciou o rendimento de carcaça, peito sem osso, coxa e sobrecoxa, asa, coração, fígado e moela, de frangos de corte, exceto pés (Tab. 3). 
Tabela 2. Ingredientes, composição percentual e valores calculados das rações para frangos de corte nas fases pré-inicial (um a sete dias), inicial (oito a 21 dias), crescimento ( 22 a 33 dias) e final ( 34 a 42 dias)

\begin{tabular}{|c|c|c|c|c|}
\hline & \multicolumn{4}{|c|}{ Ração (\%) } \\
\hline Macroingredientes & Pré-inicial & Inicial & Crescimento & Final \\
\hline Sorgo moído 8,5 & 52,87 & 56,94 & 58,51 & 63,35 \\
\hline Farelo de soja 46,0 & 40,69 & 36,68 & 34,04 & 29,07 \\
\hline Óleo vegetal & 2,71 & 2,85 & 4,17 & 4,61 \\
\hline Calcário calcítico 36\% & 1,36 & 1,38 & 1,16 & 1,45 \\
\hline Fosfato bicálcico 18.5 & 1,03 & 0,90 & 0,82 & 0,32 \\
\hline Sal comum moído & 0,50 & 0,45 & 0,38 & 0,36 \\
\hline DL-metionina $98 \%$ & 0,08 & 0,04 & 0,14 & 0,09 \\
\hline L-treonina $98 \%$ & 0,04 & 0,03 & 0,05 & 0,01 \\
\hline Premix VMA FC & $0,70^{1}$ & $0,70^{1}$ & $0,70^{2}$ & $0,70^{3}$ \\
\hline Total & 100 & 100 & 100 & 100 \\
\hline \multicolumn{5}{|l|}{ Níveis nutricionais } \\
\hline Energia metabolizável aparente $(\mathrm{kcal} / \mathrm{kg})$ & 3,050 & 3,099 & 3,219 & 3,299 \\
\hline Proteína bruta (\%) & 23,53 & 22,00 & 21,00 & 19,00 \\
\hline Ácido linoleico & 2,24 & 2,32 & 2,99 & 3,23 \\
\hline Cálcio disponível (\%) & 1,03 & 1,00 & 0,90 & 0,90 \\
\hline Fósforo disponível (\%) & 0,48 & 0,45 & 0,43 & 0,33 \\
\hline Potássio (\%) & 0,97 & 0,90 & 0,85 & 0,77 \\
\hline Sódio (\%) & 0,23 & 0,21 & 0,18 & 0,17 \\
\hline Cloro $(\%)$ & 0,37 & 0,34 & 0,31 & 0,28 \\
\hline Fibra bruta $(\%)$ & 4,39 & 4,27 & 4,15 & 4,05 \\
\hline Arginina digestível (\%) & 1,46 & 1,35 & 1,28 & 1,14 \\
\hline Isoleucina digestível (\%) & 0,97 & 0,90 & 0,86 & 0,78 \\
\hline Leucina digestível (\%) & 1,90 & 1,82 & 1,78 & 1,67 \\
\hline Lisina digestível (\%) & 1,28 & 1,18 & 1,16 & 1,00 \\
\hline Metionina digestível (\%) & 0,65 & 0,59 & 0,59 & 0,49 \\
\hline Metionina+cistina digestível (\%) & 0,96 & 0,88 & 0,87 & 0,75 \\
\hline Treonina digestível (\%) & 0,81 & 0,75 & 0,74 & 0,64 \\
\hline Triptofano digestível (\%) & 0,27 & 0,25 & 0,24 & 0,22 \\
\hline Valina digestível (\%) & 1,00 & 0,94 & 0,90 & 0,83 \\
\hline
\end{tabular}

${ }^{\mathrm{I}}$ Premix inicial (kg/ração): lisina $110 \mathrm{~g}$, metionina 350g, vit. A 1.000.000UI, vit. D3 285.700UI, vit. E 1.571UI, vit. K3 214mg, vit. B1 257mg, vit. B2 714mg, vit. B6 343mg, vit. B12 1.428,50mcg, niacina 5.000mg, ácido pantotênico $1.643 \mathrm{mg}$, ácido fólico $114,27 \mathrm{mg}$, biotina $5,70 \mathrm{mg}$, colina $42,85 \mathrm{~g}$, manganês $8.570 \mathrm{mg}$, zinco $7.140 \mathrm{mg}$, ferro $5,714 \mathrm{mg}$, cobre $1.142,86 \mathrm{mg}$, iodo $114,30 \mathrm{mg}$, selênio $42,86 \mathrm{mg}$, fitase 71.429 unidades, protease 53.571 unidades, amilase 53.571 unidades, $B$-glucanase 44.643 unidades, xilanase 89.286 unidades, celulase 80.357 unidades, etoxiquim $9.524 \mathrm{mg}$, virginamicina $2.358 \mathrm{mg}$, nicarbazina+maduramicina $6.250 \mathrm{mg}$.

${ }^{2}$ Premix crescimento (kg/ração): lisina $170 \mathrm{~g}$, metionina 230g, vit. A 785.000UI, vit. D3 171.000UI, vit. E 1.428UI, vit. K3 $171 \mathrm{mg}$, vit. B1 $171 \mathrm{mg}$, vit. B2 $571 \mathrm{mg}$, vit. B6 $271 \mathrm{mg}$, vit. B12 $1.142 \mathrm{mcg}$, niacina $4.000 \mathrm{mg}$, ácido pantotênico $1.285 \mathrm{mg}$, ácido fólico $85,70 \mathrm{mg}$, colina $37,19 \mathrm{~g}$, manganês $8.500 \mathrm{mg}$, zinco $7.100 \mathrm{mg}$, ferro $5.700 \mathrm{mg}$, cobre $1.142 \mathrm{mg}$, iodo $114 \mathrm{mg}$, selênio $35,70 \mathrm{mg}$, etoxiquim $9.430 \mathrm{mg}$, fitase 71.429 unidades, protease 53.571 unidades, amilase 53.571 unidades, $B$-glucanase 44.643 unidades, xilanase 89.286 unidades, celulase 80.357 unidades, virginamicina $2.357 \mathrm{mg}$, salinomicina $9.428,57 \mathrm{mg}$.

${ }^{3}$ Premix final (kg/ração): lisina $114 \mathrm{~g}$, metionina $187 \mathrm{~g}$, vit. A 285.714 UI, vit. D3 71.429UI, vit. E 785,71UI, vit. K3 $78,56 \mathrm{mg}$, vit. B2 285,70mg, vit. B12 714,28mcg, niacina $2.857 \mathrm{mg}$, ácido pantotênico $928,60 \mathrm{mg}$, colina $17,10 \mathrm{~g}$, manganês $8.570 \mathrm{mg}$, zinco $7.143 \mathrm{mg}$, ferro $5.714 \mathrm{mg}$, cobre $1.142,86 \mathrm{mg}$, iodo $114,30 \mathrm{mg}$, selênio $28,57 \mathrm{mg}$, fitase 71.430 unidades, protease 53.571 unidades, amilase 53.571 unidades, $B$-glucanase 44.643 unidades, xilanase 89.286 unidades, celulase 80.357 unidades, etoxiquim $9.524 \mathrm{mg}$. 
Tabela 3. Rendimento de carcaça e cortes de frangos de corte de duas linhagens aos 42 dias de idade, criados em diferentes tempos de exposição à temperatura ambiente elevada

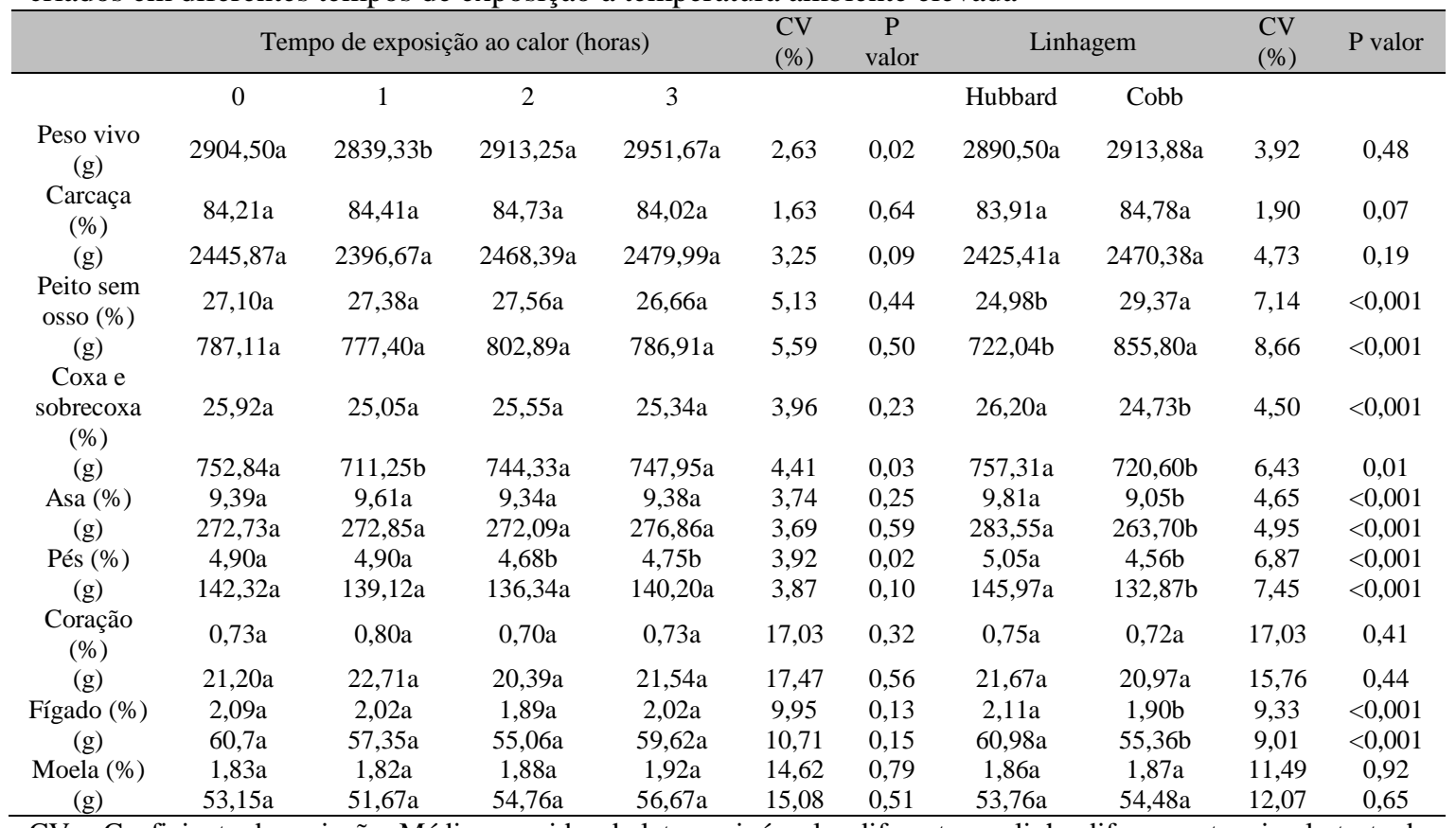

$\mathrm{CV}=$ Coeficiente de variação. Médias seguidas de letras minúsculas diferentes na linha diferem entre si pelo teste de Scott-Knott a $5 \%$.

Uma possível explicação é o fato de que as aves compensaram os efeitos deletérios do estresse nas demais horas do dia. Tal resultado foi semelhante ao apresentado por Diniz e colaboradores (2014), que não verificaram influência da temperatura no rendimento de carcaça fria, peito, coxa, asa em frangos de corte da linhagem $\mathrm{Cobb}{ }^{\circledR}$ abatidos aos 42 dias e criados em temperatura que variou de $12,02^{\circ} \mathrm{C}$ a $36,8^{\circ} \mathrm{C}$ em galpão convencional, em relação aos mantidos em temperatura termoneutra ideal.

Esses resultados corroboram os de Fernandes et al. (2013), que observaram frangos da linhagem Ross submetidos ao frio e ao calor na primeira semana de vida, os quais foram divididos, dos 35 aos 42 dias de idade, em dois ambientes: conforto térmico $\left(26^{\circ} \mathrm{C}\right)$ e estresse por calor $\left(32^{\circ} \mathrm{C}\right)$. As altas temperaturas às quais as aves foram submetidas na última semana pré-abate afetaram o rendimento de carcaça, devido à resposta de adaptação à prévia exposição à variação de temperatura, à qual foram submetidas na primeira semana de vida.

O rendimento de peito de frangos da linhagem Cobb foi reduzido pela exposição ao calor durante todo o período de criação (Boiago et al.,
2013). O estresse cíclico por calor durante uma hora diária, do $16^{\circ}$ ao $42^{\circ}$ dia de idade, também diminuiu o peso absoluto do peito sem osso de frangos de corte da linhagem Cobb Avian $48^{\mathrm{TM}}$, porém não prejudicou o rendimento de carcaça, cortes e vísceras comestíveis, o que sugere que temperatura elevada altera o metabolismo de proteína, de maneira que os músculos da coxa e da sobrecoxa são priorizados em comparação ao peito (Marchini, 2012), devido ao fato de as fibras do peito serem predominantemente do tipo IIb, pobres em mioglobina, de contração rápida e glicolíticas, com menor demanda de irrigação sanguínea e oxigênio, enquanto as da coxa e da sobrecoxa são predominantemente do tipo I, ricas em mioglobina, contração lenta e oxidativas, com maior demanda de irrigação e oxigênio (Ono et al., 1993).

Faria Filho (2003), ao estudar frangos Cobb 500 sob temperaturas fria, termoneutra e quente, dos sete aos 21 dias de idade, verificou que aves abatidas aos 21 dias tiveram o rendimento de peito reduzido e o de coxa e sobrecoxa e asas aumentado, devido à ofegação para aumentar a perda de calor, causando maior atividade da musculatura do peito, o que prejudica o seu desenvolvimento. As aves criadas em 
temperatura termoneutra até 21 dias e submetidas ao estresse por calor dos 21 aos 42 dias apresentaram rendimento de carcaça e coxa e sobrecoxa maior em relação às criadas sob frio e conforto, enquanto o rendimento das asas foi maior que em temperatura fria. $\mathrm{O}$ maior rendimento de carcaça provavelmente ocorreu devido ao menor empenamento, ocasionado pela necessidade de dissipar calor, e ao menor desenvolvimento visceral das aves em temperaturas quentes.

Oba et al. (2012) verificaram que frangos da linhagem Cobb, sob temperatura quente, do primeiro ao $47^{\circ}$ dia de idade, apresentaram maior rendimento de carcaça $(73,26 \%)$, que em temperatura termoneutra $(71,20 \%)$ e fria $(69,90 \%)$. Os autores afirmam que esses resultados podem ser devido à redução da ingestão de ração no ambiente quente, que leva ao menor desenvolvimento das vísceras e, por consequência, ao maior rendimento da carcaça. Os frangos mantidos em estresse pelo calor apresentaram menor rendimento de peito $(31,98 \%)$ e maior rendimento de pernas $(34,65 \%)$, em comparação com as aves mantidas nas demais temperaturas.

Também Sands e Smith (1999) observaram que frangos de corte submetidos a quatro horas diárias ao estresse por calor $\left(35^{\circ} \mathrm{C}\right)$, dos 22 aos 49 dias, apresentaram aumento no rendimento de carcaça e pernas e redução no rendimento de peito, em comparação ao ambiente termoneutro. Oliveira Neto et al. (2000) mantiveram frangos da linhagem Hubbard, criados em temperaturas quentes constantes $\left(32,3 \pm 0,31^{\circ} \mathrm{C}\right)$ dos 21 aos 42 dias de idade, e observaram maior rendimento de carcaça, devido ao menor peso absoluto das penas e dos órgãos.

Aïn Baziz et al. (1996) observaram redução no rendimento de peito de frangos de corte expostos cronicamente ao calor $\left(32^{\circ} \mathrm{C}\right)$ após a quarta semana de idade, enquanto coxa e sobrecoxa e carcaça aumentaram. Os autores explicam essa diferença do efeito da temperatura elevada em razão das características das fibras, sendo as do peito glicolíticas e as das pernas oxidativas, e, portanto, seus substratos são predominantemente glicose e ácidos graxos, respectivamente. Afirmam ainda que a redução no crescimento muscular sob exposição ao calor sugere mudanças no metabolismo proteico pelas modificações na síntese ou degradação de proteínas.

Aves expostas às altas temperaturas $\left(32^{\circ} \mathrm{C}\right)$ a partir dos 21 dias apresentaram maior rendimento de carcaça $(85 \%)$, quando comparadas às aves criadas em conforto térmico $(82,6 \%)$, o que pode ser explicado pelo menor peso de órgãos nas aves submetidas a elevadas temperaturas ambientais; além disso, apresentaram também maior rendimento de coxa $(13,6 \%)$ e sobrecoxa (14\%) e menor rendimento de peito $(26,7 \%)$, quando comparadas às aves criadas em conforto térmico (coxa 12,4\%, sobrecoxa $12,5 \%$, peito $27,2 \%$ ). Isso se deve à influência da alta temperatura no metabolismo de proteínas, que, nessas condições, tem prioridade de deposição na coxa, e não no músculo do peito (Oliveira et al., 2006).

Rosa et al. (2007) encontraram maiores rendimentos de carcaça e de coxa e sobrecoxa em frangos submetidos ao estresse por calor, $32^{\circ} \mathrm{C}$, a partir dos 28 dias. Esse estudo revelou ainda redução no desenvolvimento de vísceras devido ao melhoramento genético, o que contribuiu para melhor rendimento de carcaça.

Aves da linhagem Cobb submetidas ao estresse por calor de $32^{\circ} \mathrm{C}$, por 72 horas, a partir de 21 dias de idade, apresentaram menor rendimento de peito nessa idade em comparação às aves submetidas ao calor a partir de 35 dias (Mello et al., 2015), porém essa alteração no rendimento do peito não pode ser atribuída somente ao estresse por calor, mas também ao crescimento das aves ao longo do tempo. Plavnik e Yahav (1998) submeteram frangos de corte ao estresse por calor, a partir da quarta semana de idade, em temperatura de $35^{\circ} \mathrm{C}$, das sete às 19 horas, e em temperatura de $25^{\circ} \mathrm{C}$, das 19 às sete horas. $\mathrm{O}$ rendimento de peito diminuiu $8 \%$ em relação aos frangos mantidos em temperatura ideal.

Oliveira Neto et al. (2000) e Oliveira et al. (2006) observaram que, ao submeterem frangos de corte à alta temperatura constante $\left(32^{\circ} \mathrm{C}\right)$ por 24 horas, estes apresentaram menores pesos relativos de moela, fígado e coração. Os autores utilizaram as linhagens Hubbard e Avian, respectivamente, resultado que difere do presente estudo possivelmente devido à intensidade e duração diária ao estresse. 
A linhagem Cobb 500 Slow ${ }^{\circledR}$ apresentou maior rendimento de peito sem osso, menor rendimento de coxa e sobrecoxa, asa, pés e fígado em comparação à linhagem Hubbard Flex® (Tab. 3). Esses resultados provavelmente ocorreram devido à melhor adaptabilidade da linhagem Hubbard ao calor. Carolino et al. (2014), em termoneutralidade, verificaram que frangos da linhagem Hubbard Flex apresentaram maiores rendimentos de asa $(10,84 \%)$ e peito $(28,63 \%)$ que os apresentados na presente pesquisa e rendimento similar de coxa e sobrecoxa $(26,20 \%)$.

Fernandes et al. (2002) investigaram os cruzamentos genéticos entre as linhagens Ross, Hubbard e Isa Vedette. O cruzamento Isa Vedette x Hubbard apresentou maior proporção de peito com osso em relação aos demais nos abates de 42 e 44 dias e redução proporcional no rendimento de sobrecoxa apenas no abate de 44 dias. Isso ocorreu devido ao maior crescimento da musculatura esquelética de órgãos de suporte, como da digestão. O aumento do peito é desejável, por ser um corte de maior valor econômico comparado aos demais cortes.

Neste estudo, a linhagem Cobb 500 Slow ${ }^{\circledR}$ apresentou maior percentual de extrato etéreo e menor percentual de proteína e matéria mineral em relação à linhagem Hubbard Flex $®$, enquanto a matéria seca não diferiu (Tab. 4). Esses resultados discordam dos encontrados por Twining et al. (1978), que, em condições normais de temperatura, observaram que, aos 28 dias de idade, as aves de linhagem Cobb apresentavam mais proteína e umidade na carne que a linhagem Hubbard, enquanto aos 49 dias não diferiram.

Tabela 4. Composição de peito de frangos de corte de duas linhagens, aos 42 dias de idade, criados em diferentes tempos de exposição, em temperatura ambiente elevada

\begin{tabular}{ccccc}
\hline Linhagem & Extrato etéreo (\%) & Proteína $(\%)$ & $\begin{array}{c}\text { Matéria seca } \\
(\%)\end{array}$ & $\begin{array}{c}\text { Matéria mineral* } \\
(\%)\end{array}$ \\
\hline Hubbard Flex® & & $80,89 \mathrm{a}$ & $29,06 \mathrm{a}$ & $4,66 \mathrm{a}$ \\
Cobb 500 Slow® & $9,37 \mathrm{a}$ & $77,26 \mathrm{~b}$ & $29,38 \mathrm{a}$ & $4,41 \mathrm{~b}$ \\
Coeficiente de variação & $12,71 \mathrm{~b}$ & 3,14 & 5,36 & 7,72 \\
P-valor & 28,06 & $<0,001$ & 0,4902 & 0,0225 \\
Tempo de exposição ao calor & $<0,001$ & & & \\
0 & & $80,70 \mathrm{a}$ & $29,65 \mathrm{a}$ & $4,60 \mathrm{a}$ \\
1 & $11,11 \mathrm{a}$ & $78,42 \mathrm{a}$ & $29,06 \mathrm{a}$ & $4,41 \mathrm{a}$ \\
2 & $10,12 \mathrm{a}$ & $79,09 \mathrm{a}$ & $28,95 \mathrm{a}$ & $4,63 \mathrm{a}$ \\
3 & $11,78 \mathrm{a}$ & $78,09 \mathrm{a}$ & $29,23 \mathrm{a}$ & $4,50 \mathrm{a}$ \\
P-valor & $11,15 \mathrm{a}$ & 3,58 & 4,83 & 8,87 \\
Coeficiente de variac̃ão $(\%)$ & 23,85 & 0,1555 & 0,6373 & 0,5548 \\
\hline
\end{tabular}

Médias seguidas de letras minúsculas diferentes na coluna diferem entre si pelo teste de Scott-Knott a 5\%.

*Calculados com base na matéria seca.

O estresse cíclico por calor durante uma, duas e três horas não influenciou o extrato etéreo, a proteína, a matéria seca e a matéria mineral (Tab. 4). Esses resultados corroboram o de Diniz et al. (2014), que não verificaram influência da temperatura $\left(12,02^{\circ} \mathrm{C}\right.$ a $36,8^{\circ} \mathrm{C}$ por 42 dias) no teor de proteína bruta, umidade, extrato etéreo e cinzas na carne de frangos de corte da linhagem Cobb®. Os autores explicam esse resultado devido ao fato de que o período de exposição ao calor pode não ter sido suficiente para provocar alterações.
Também Faria Filho et al. (2006), ao submeterem frangos Cobb 500 às temperaturas de $20 ; 25,1 ; 32,2^{\circ} \mathrm{C}$ dos 42 aos 49 dias de idade, não observaram influência da temperatura na composição de matéria seca, proteína bruta, extrato etéreo e matéria mineral do peito.

Já Tankson et al. (2001) observaram redução no teor de proteína do peito de aves submetidas ao calor a partir do $36^{\circ}$ dia de criação, em que se aumentou gradualmente das seis às 14 horas até serem atingidos $34^{\circ} \mathrm{C}$. Brossi (2007) observou menor teor de umidade, lipídios e cinzas, ao submeter aves da linhagem Cobb 500 ao calor $\left(35^{\circ} \mathrm{C}\right)$ durante duas horas antes do abate. 
Concluíram que mudanças no perfil da carne ocorreram na tentativa do organismo em buscar a homeostase ao ser submetido ao estresse térmico induzido no pré-abate.

\section{CONCLUSÃO}

O estresse cíclico por calor por até três horas diárias do $14^{\circ}$ dia ao $41^{\circ}$ não influencia o rendimento de carcaça, cortes e vísceras comestíveis, bem como a composição química do peito de frangos Cobb 500 Slow ${ }^{\circledR}$ e Hubbard Flex®. A linhagem Cobb é mais indicada à produção de peito, enquanto a linhagem Hubbard ao comércio de frango inteiro.

\section{AGRADECIMENTOS}

À Fapemig (Fundação de Amparo à Pesquisa do Estado de Minas Gerais), pelo financiamento da pesquisa (Universal APQ- 01292-13).

\section{REFERÊNCIAS}

AÏN BAZIZ, H.; GERAERT, P.A.; PADILHA, J.C.F.; GUILLAUMIN, S. Chronic heat exposure enhances fat deposition and modifies muscle and fat partition in broiler carcasses. Poult. Sci., v.75, p.505-513, 1996.

ANTONIO, J. Efeito da temperatura e da restrição alimentar sobre o desempenho, composição de carcaça e padrões de expressão de genes do eixo somatotrófico em frangos de corte. 2010. 86f. Dissertação (Mestrado em Zootecnia) - Faculdade de Ciências Agrárias e Veterinárias, Universidade Estadual Paulista, Jaboticabal, SP.

BOIAGO, M.M.; BORBA, H.; SOUZA, P.A. et al. Desempenho de frangos de corte alimentados com dietas contendo diferentes fontes de selênio, zinco e manganês, criados sob condições de estresse térmico. Arq. Bras. Med. Vet. Zootec., v.65, p.241-247, 2013.

BRASIL. Ministério da Agricultura, Pecuária e Abastecimento. Portaria $n^{\circ} 210$ de 1998 de 10 de novembro de 1998. Aprovar o Regulamento Técnico da Inspeção Tecnológica e Higiênico-Sanitária de Carne de Aves. Diário Oficial da União, Brasília. Seção 1. p.226, 26 nov. 1998.

BRASIL. Ministério da Agricultura, Pecuária e Abastecimento. Sindicato Nacional da Indústria de Alimentação Animal. Associação Brasileira da Indústria de Alimentação Animal. Colégio Brasileiro de Nutrição Animal. Métodos analíticos. In: Compêndio Brasileiro de Alimentação Animal. São Paulo: Sindirações, 2009.
BROSSI, C. Qualidade da carne de frango: efeito do estresse severo pré-abate, classificação pelo uso da carne marinação. 2007. 108f. Dissertaçao (Mestrado em Ciência e Tecnologia de alimentos) - Faculdade de Zootecnia, Escola Superior de Agricultura Luiz de Queiroz, Piracicaba, SP.

CAROLINO, A.C.X.G.; SILVA, M.C.A.; LITZ, F.H et al. Rendimento e composição de carcaça de frangos de corte alimentados com dietas contendo sorgo grão inteiro. Biosci. J., v.30, p.1139-1148, 2014.

DINIZ, T.; BORBA, H.; MELLO, J.L.M. et al. Efeito da temperatura ambiente e reutilização da cama na qualidade da carne de frangos de corte. CES Med. Vet. Zootec., v.9, p.218-226, 2014.

FARIA FILHO, D. E. Efeito de dietas com baixo teor protéico, formuladas usando o conceito de proteína ideal, para frangos de corte criados em temperaturas fria, termoneutra e quente. 2003. 93f. Dissertação (Mestrado em Zootecnia) - Universidade Estadual Paulista, Jaboticabal.

FARIA FILHO, D.E.; ROSA, P.S.; FIGUEIREDO, D.F.; MACARI, F.D.M.; FURLAN, R.L. Dietas de baixa proteína no desempenho de frangos criados em diferentes temperaturas. Pesqui. Agropec. Bras., v.41, p.101-106, 2006.

FERNANDES, J.I.M.; SCAPINI, L.B.; GOTTARDO, E. et al. Thermal conditioning during the first week on performance, heart morphology and carcass yield of broilers submitted to heat stress. Acta Sci. Anim. Sci., v.35, p.311-319, 2013.

FERNANDES, L.M.; VIEIRA, S.L.; BAPTISTA, C.B. Desenvolvimento de 51 órgãos da digestão e rendimento de carcaça de frangos de corte de diversas origens genéticas criados com bebedouros pendular e nipple. Rev. Bras. Ciênc. Avíc., v.4, p.1-12, 2002.

FERREIRA, D.F. Sisvar: a computer statistical analysis system. Ciênc. Agrotec., v.35, p.1039-1042, 2011.

MARCHINI, C.F.P. Desempenho, alterações ósseas e intestinais de frangos de corte submetidos ao estresse cíclico por calor. 2012. 108f. Tese (Doutorado em Ciência Animal) - Universidade Federal de Goiás, Escola de Veterinária e Zootecnia, GO.

MELLO, J.L.M.; BOIAGO, M.M.; GIAMPIETROGANECO, A. et al. Periods of heat stress during the growing affects negatively the performance and carcass yield of broilers. Arch. Zootec., v.64, p.339$345,2015$.

OBA, A.; LOPES, P.C.F.; BOIAGO, M.M. et al. Características produtivas e imunológicas de frangos de corte submetidos a dietas suplementadas com cromo, criados sob diferentes condições de ambiente. Rev. Bras. Zootec., v.41, p.1186-1192, 2012. 
OLIVEIRA NETO, A.R.; OLIVEIRA, R.F.M.; DONZELE, J.L. et al. Efeito da temperatura ambiente sobre o desempenho e característica de carcaça de frangos de corte alimentados com dieta controlada e dois níveis de energia metabolizável. Rev. Bras. Zootec., v.29, p.183-190, 2000.

OLIVEIRA, G.A.; OLIVEIRA, R.F.M.; DONZELE, J.L. et al. Efeito da temperatura ambiente sobre o desempenho e as características de carcaça de frangos de corte dos 22 aos 42 dias. Rev. Bras. Zootec., v.35, p.1398-1405, 2006.

ONO, Y.; IWAMOTO, H.; TAKAHARA, H. The relationship between muscle growth and the growth of different fiber types in the chicken. Poult. Sci., v.72, p.568-576, 1993.

PLAVNIK, I.; YAHAV, S. Effect of environmental temperature on broiler chickens subjected to growth restriction at an early age. Poult. Sci., v.77, p.870-872, 1998.

ROSA, P.S.; FARIA FILHO, D.E.; DAHLKE, F. et al. Performance and carcass characteristics of broiler chickens with different growth potential and submitted to heat stress. Rev. Bras. Ciênc. Avíc., v.9, p.181-186, 2007.
ROSTAGNO, H.S.; ALBINO, L.F.T.; DONZELE, J.L. et al. Tabelas brasileiras para aves e suínos: composição de alimentos e exigências nutricionais. Viçosa: UFV, 2011. 252p.

SANDS, J.S.; SMITH, M.O. Broilers in heat stress conditions: effects of dietary manganese proteinate or chromium picolinate supplementation. J. Appl. Poult. Res., v.8, p.280-287, 1999.

SILVA, M.T.P. Desempenho e características de carcaça de três genótipos comerciais de frangos de corte alimentados com diferentes dietas. 2013. 31f. Dissertação (Mestre em Zootecnia) - Universidade Federal dos Vales do Jequitinhonha e Mucuri, Diamantina, MG.

TANKSON, J.D.; VIZZIER, T.Y.; THAXTON, J.P. et al. Stress and nutritional quality of broilers. Poult. Sci., v.80, p.1384-1389, 2001.

TWINING JR, P.V.; THOMAS, O.P.; BOSSARD, E.H. Effect of diet and type of birds on the carcass composition of broilers at 28,49 and 59 days of age. Poult. Sci., v.57, p.492-497, 1978.

ZHANG, Z.Y.; JIA, G.Q.; ZUO, J.J. et al. Effects of constant and cyclic heat stress on muscle metabolism and meat quality of broiler breast fillet and thigh meat. Poult. Sci., v.91. p.2931-2937, 2014. 